\title{
Impact of the Asian Chestnut Gall Wasp, Dryocosmus kuriphilus (Hymenoptera, Cynipidae), on the Chestnut Component of Honey in the Southern Swiss Alps
}

\author{
Eric Gehring, ${ }^{1,2,6}$ Christina Kast, ${ }^{3}$ Verena Kilchenmann, ${ }^{3}$ Katharina Bieri, ${ }^{4}$ Regula Gehrig, ${ }^{5}$ \\ Gianni B. Pezzatti, ${ }^{1}$ and Marco Conedera ${ }^{1}$
}

\begin{abstract}
'Swiss Federal Institute for Forest, Snow and Landscape Research WSL, Insubric Ecosystems Research Group, A Ramél 18, Cadenazzo CH-6593, Switzerland, 2University of Neuchâtel, Laboratory of Soil Biology, Emile-Argand 11, Neuchâtel CH-2000, Switzerland, ${ }^{3}$ Agroscope, Swiss Bee Research Center, Schwarzenburgstrasse 161, Berne CH-3003, Switzerland, ${ }^{4}$ Biologisches Institut für Pollenanalyse K. Bieri GmbH, Kehrsatz CH-3122, Switzerland, ${ }^{5}$ Federal Office of Meteorology and Climatology MeteoSwiss, Zürich-Flughafen $\mathrm{CH}-8058$, Switzerland, and ${ }^{6}$ Corresponding author, e-mail: eric.gehring@wsl.ch
\end{abstract}

Subject Editor: John Trumble

Received 7 September 2017; Editorial decision 14 November 2017

\begin{abstract}
The Asian chestnut gall wasp (ACGW; Dryocosmus kuriphilus Yasumatsu, Hymenoptera, Cynipidae) is considered as one of the most dangerous pests of the genus Castanea. In southern Switzerland, repeated heavy ACGW attacks prevented chestnut trees from vegetating normally for years before the arrival and spread of the biological control agent Torymus sinensis (Kamijo, Hymenoptera, Torymidae). This resulted in a greatly reduced green biomass and flower production. In this paper, we analyze the impact of such an ecosystem alteration of the environment on the composition of produced honey. Six beekeepers were chosen from sites with different densities of chestnut trees, each of which providing series of honey samples from 2010 to 2016. We determined the chestnut component in the honeys via a combined chemical and sensory approach, and correlated the obtained results with the degree of yearly ACGW-induced crown damage and weather conditions during the period in question in the surrounding chestnut stands. The chestnut component in the analyzed honey sample series showed a strong correlation with the degree of ACGW-induced crown damage, whereas meteorological conditions of the corresponding year had a very marginal effect. Decreases in the chestnut component of the honey were statistically significant starting from a ACGW infestation level of $30 \%$.
\end{abstract}

Key words: Castanea sativa, invasive pest, chestnut honey, honey sensory analysis, tree damage

The Asian chestnut gall wasp (ACGW; Dryocosmus kuriphilus Yasumatsu, Hymenoptera, Cynipidae) is a univoltine thelytokous (females only) species native to China that attacks different species of the chestnut genus Castanea (Moriya et al. 2003). Because of its huge parthenogenetic reproductive capacity and the negative effect on shoot, flower, and fruit production caused by gall formation, D. kuriphilus is considered to be one of the most dangerous pests of the genus Castanea (Payne et al. 1983, Moriya et al. 1990, Aebi et al. 2006). In newly invaded regions of the world where no specific natural enemies are present, ACGW outbreaks over multiple years result in severely malformed branch architectures including a decrease of dormant buds and an increase of dead shoots with leaf area losses of up to $70 \%$ (Gehring et al. 2017), nut yield reductions of up to $80 \%$ (Battisti et al. 2014, Sartor et al. 2015), and corresponding reductions in tree vigor and wood production (Ugolini et al. 2014).
In Europe, D. kuriphilus was reported for the first time in 2002 in the Cuneo region (Piedmont, Italy; Brussino et al. 2002), from where it progressively spread to the rest of Italy and most European chestnut-growing countries (EPPO 2017). In Switzerland, the first occurrence of D. kuriphilus dates back to 2007 (Forster et al. 2009) when it was found in the southernmost part of Canton Ticino, from where the ACGW spread throughout the whole chestnut area of southern Switzerland by 2013 (Conedera et al. 2016).

Following the successful Japanese experience of biologically controlling D. kuriphilus by introducing the chalcid parasitoid Torymus sinensis (Kamijo, Hymenoptera, Torymidae) from mainland China, this specific parasitoid was introduced in 2005 into Piedmont (northern Italy), where it was found to be very efficient in controlling the ACGW population (Quacchia et al. 2008, 2014) also on Castanea sativa (Miller, Fagales, Fagaceae) native to Europe and Asia Minor. Unlike Italy and other European countries such as France 
(Borowiec et al. 2014), Croatia, Slovenia, and Hungary (Matošević et al. 2015), the permission to introduce the biocontrol agent $T$. sinensis to control the ACGW was not granted in Switzerland due to open environmental questions (e.g., potential of hybridization between T. sinensis and native Torymus species and attacks on nontarget native gall wasps, Gibbs et al. 2011). Nevertheless, T. sinensis benefited from unauthorized introductions and/or natural cross-border emigration from nearby Italian releases, resulting in its official detection over the entire chestnut area of southern Switzerland by 2013 (Gehring et al. 2014) and on the biological control impact of the ACGW by 2015 (Gehring et al. 2017). Because of the extended time-lag in the arrival of $T$. sinensis, part of the chestnut forests in southern Switzerland experienced up to $7 \mathrm{yr}$ of undisturbed and repeated ACGW attacks, preventing chestnut trees from vegetating normally, and causing a progressive malformation of branch architecture and a strong reduction in the production of leaves and flowers (Gehring et al. 2017). This damage may have not only impacted chestnut fruit production but also the chestnut component in the locally produced honey.

In this study, we verify this conjecture by analyzing the impact of ACGW-induced damage on chestnut trees and on the composition of honey produced during the ACGW epidemic phase that started in 2010, became impacting between 2011 and 2012, peaked between 2012 and 2014, and progressively lessened between 2015 and 2016 according to the different sites (Gehring et al. 2017). We, in particular, hypothesize that the chestnut component in honey undergoes a significant reduction when D. kuriphilus damage on tree crowns is high and widespread. The following detailed questions are addressed in this study:

- How can we assess the chestnut component in honey?

- Do changes in chestnut components in honey correlate with tree damage due to D. kuriphilus infestation?

- Do meteorological conditions during chestnut flowering have a detectable influence on chestnut component in honey?

- Are there any ACGW damage thresholds beyond which the alteration of the chestnut component in honey is statistically significant?

\section{Material and Methods}

\section{Study Area}

The study area is represented by the chestnut forest of Canton Ticino, in southern Switzerland (Fig. 1). The chestnut tree (C. sativa Mill.) was introduced to the study area nearly 2,000 yr ago (Tinner et al. 1999). Since then, in Canton Ticino, it has spread and been cultivated by man as a monoculture for timber and fruit production (Conedera et al. 2004) at elevations ranging from $200 \mathrm{~m}$ (lowest point in the area at Lago Maggiore) up to the ecological limits of the species at 900 to $1,100 \mathrm{~m}$ asl. (Conedera et al. 2001). Where the steep mountain slopes restrict alternative agricultural or commercial activities, chestnut cultivation for staple-food production became the main source of subsistence for local populations (Krebs et al. 2012). The decline in the economic importance of the chestnut tree began in the study area in the early 1800s, when alternative crops such as potatoes and maize were introduced and accelerated in the late 1950 s coinciding with the rapid post-war socioeconomic development of the area (Krebs et al. 2014). As a result, most of the former chestnut stands are now abandoned and subjected to a post-cultural evolution toward mixed broadleaved forests dominated by native tree species such as lime tree (Tilia spp.), deciduous oaks (Quercus spp.), ash (Fraxinus spp.), and maple (Acer spp.) depending on site conditions (Conedera et al. 2001, Pividori et al. 2005). Consequently,

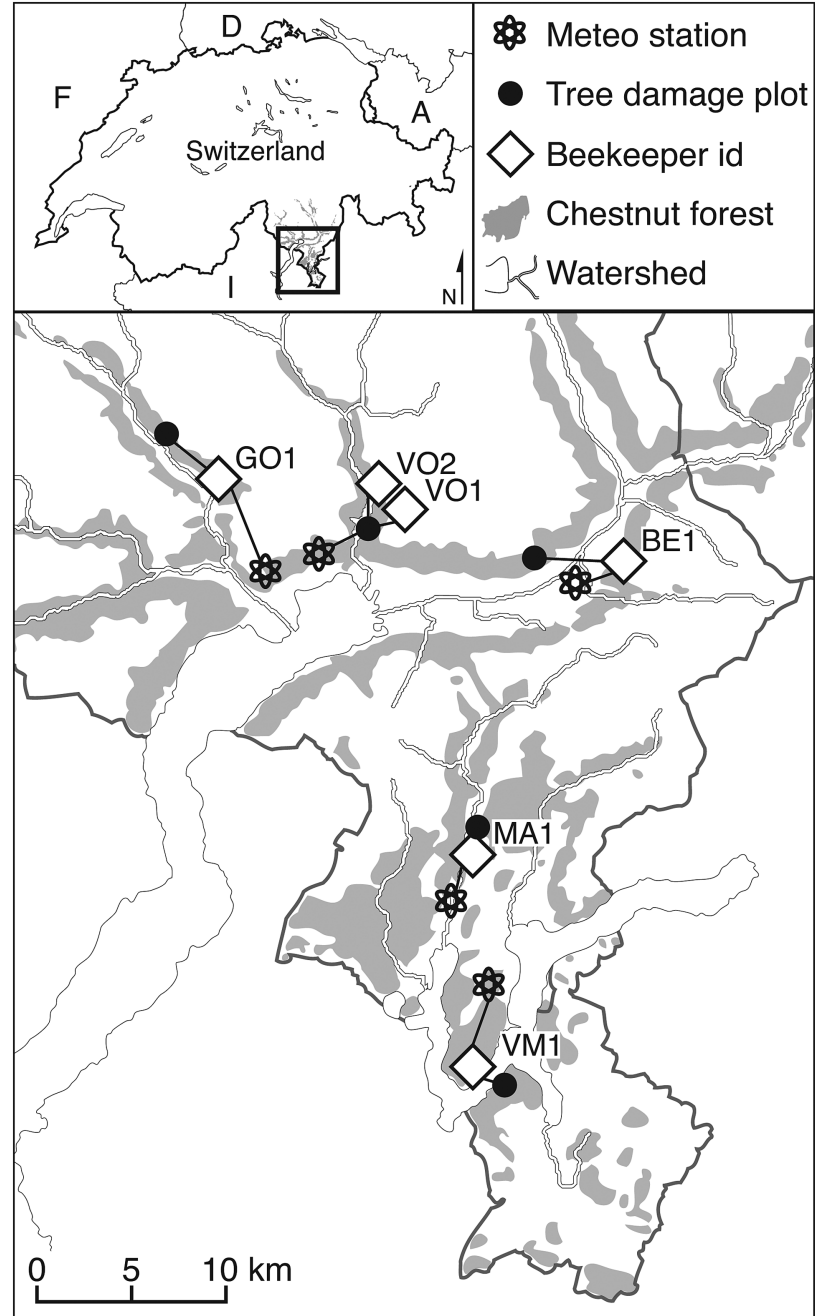

Fig. 1. Map of the study area with the location of honey production sites and related chestnut tree damage plots and meteorological stations.

the present chestnut tree contribution to forest composition varies strongly as a function of the degree of forest stand abandonment or possible management activities by forest owners, respectively (Krebs et al. 2014).

During its flowering period occurring over about 1 mo but stretching from the beginning of June to the end of July depending on the season, the chestnut tree represents one of the best nectar and pollen sources for bees (Maurizio and Schaper 1994, Persano Oddo and Pirro 2004, Aronne et al. 2012, Yang et al. 2012). Furthermore, aphids that are often hosted on young chestnut shoots can produce additional honeydew. Accordingly, local honey production during this season ranges from highly sought-after chestnut unifloral (Persano Oddo and Piro 2004, Apisuisse 2015) to chestnut-poor honeys (defined in section 2.3. and Table 1) as a function of the density of the chestnut tree and other nectar-providing species at production sites. These include Rubus spp., Rhododendron spp., and Tilia spp., all of which flower in the same period.

\section{Sampling Design}

In order to minimize potential bias in our experimental design due to honey production techniques (Aronne and de Micco 2010), we considered only honey samples that fulfilled the following criteria: 1) their production sites (hive location) remained constant for the 
Table 1. Beekeepers and beehive site characteristics

\begin{tabular}{|c|c|c|c|c|c|c|c|c|c|c|c|}
\hline \multirow[b]{2}{*}{ Beekeeper } & \multirow[b]{2}{*}{ Municipality } & \multirow[b]{2}{*}{ Samples } & \multirow[b]{2}{*}{$\begin{array}{c}\text { Dryocosmus } \\
\text { kuriphilus }\end{array}$} & \multirow[b]{2}{*}{$\begin{array}{l}\text { Torymus } \\
\text { sinensis }\end{array}$} & \multirow[b]{2}{*}{ Honey $^{a}$} & \multicolumn{6}{|c|}{ Beehive location } \\
\hline & & & & & & Lat & Long & Altitude & Aspect & $\begin{array}{l}\text { Distance } \\
\text { from tree } \\
\text { damage } \\
\text { plot }\end{array}$ & $\begin{array}{c}\text { Distance } \\
\text { from } \\
\text { meteo } \\
\text { station }\end{array}$ \\
\hline \multicolumn{2}{|l|}{ Code } & \multirow{2}{*}{$\frac{\text { No. }}{7}$} & \multicolumn{2}{|c|}{ Arrival year } & \multirow{2}{*}{$\begin{array}{c}\text { Type } \\
\text { Moderate }\end{array}$} & \multicolumn{2}{|c|}{$\begin{array}{c}\text { WGS } 84 \text { Decimal } \\
\text { Degrees }\end{array}$} & \multirow{2}{*}{$\frac{\mathrm{m} \text { asl }}{480}$} & \multirow{2}{*}{$\begin{array}{c}\circ \\
\text { S-SE }\end{array}$} & \multirow{2}{*}{$\frac{\mathrm{km}}{2.3}$} & \multirow{2}{*}{$\frac{\mathrm{km}}{4.1}$} \\
\hline VM1 & Vico Morcote & & 2010 & 2012 & & 45.93130 & 8.92059 & & & & \\
\hline MA1 & Manno & 7 & 2010 & 2012 & Moderate & 46.03836 & 8.92156 & 340 & S-E & 1.5 & 3.1 \\
\hline BE1 & Bellinzona & $5^{b}$ & 2011 & 2012 & Unifloral & 46.18364 & 9.03497 & 500 & $\mathrm{~N}$ & 5.0 & 3.3 \\
\hline VO1 & Vogorno & 7 & 2011 & 2012 & Moderate & 46.22505 & 8.85844 & 610 & SW & 2.7 & 5.2 \\
\hline VO2 & Vogorno & $6^{c}$ & 2011 & 2012 & Moderate & 46.22613 & 8.85797 & 660 & SW & 2.5 & 5.0 \\
\hline GO1 & Gordevio & 7 & 2012 & 2013 & Poor & 46.22943 & 8.74507 & 365 & SW & 4.2 & 6.3 \\
\hline
\end{tabular}

${ }^{a}$ Chestnut honey type before or at time of Dryocosmus kuriphilus arrival year; Unifloral = electrical conductivity $>0.86 \mathrm{mS} / \mathrm{cm}$, free acids $<22.4 \mathrm{meq} / \mathrm{kg}$ and sensory level of Castanea sativa is maximal and exclusive (RCS $=1$ ); Moderate $=$ RCS $<1$ and Csc $\geq 0.10$; Poor $=$ RCS $>0$ and Csc values $<0.10$. RCS $=$ chestnut sensory level/cumulated overall sensory levels (chestnut + lime + mixed flowers + honeydew). Csc $=$ Electrical conductivity/free acids $*(1+\mathrm{RCS})$.

${ }^{b}$ Honey samples not available for 2010 and 2013.

${ }^{c}$ Honey samples not available for 2011.

entire study period (sedentary beekeeping); 2) beekeeping (hive and comb types) and honey production approaches remained unchanged (single honey extraction after chestnut flowering at the beginning of August using the same method) over the whole study period; 3) wellconserved (e.g., no odor or flavor of fermentation or other alterations) honey samples were available under similar storage conditions (e.g., hermetic container, consistent temperatures of approximately 10-15 degree Celsius $\left({ }^{\circ} \mathrm{C}\right)$, no direct sunlight); 4) the selected hive sites were characterized by a nearly synchronic epidemiology of D. kuriphilus concerning both the year of arrival of D. kuriphilus and $T$. sinensis and subsequent chestnut tree recovery with no late frost events that could potentially destroy chestnut flowering during the study period.

Six beekeepers within a geographic area extending from the Lake of Lugano in the south to the lowlands of the upper valleys (Fig. 1) met all of these conditions over a time span of 7 yr (2010-2016). One producer (VO2) delivered only six (honey sample not available for 2011) and another (BE1) only five (the 2010 honey sample was not well conserved and fermented, and the 2013 sample was not available) honey samples in the requested quality and quantity, for a total sample size of 39 samples (see details in Table 1).

\section{Assessing the Chestnut Component in Honey}

Unifloral chestnut honey is highly characteristic in terms of odor and flavor. Chestnut honey typically has a strong bitter taste and is astringent. The intense flavor can be described as woody, warm, chemical, with a long persistence (Persano Oddo and Piro 2004). High electrical conductivity (average 1.3 milliSiemens per centimeter $(\mathrm{mS} / \mathrm{cm})$; range 0.86 to $1.70 \mathrm{mS} / \mathrm{cm}$; Bogdanov et al. 2008) and low free acidity (average of 11.2 milliequivalents (meq/kg); range 6.7 to $22.4 \mathrm{meq} / \mathrm{kg}$; Bogdanov et al. 2008) are typical physicochemical characteristics of chestnut honey (Persano Oddo and Piro 2004, Ruoff et al. 2007). When the chestnut component in the honey is less prominent or low, these physicochemical characteristics and the corresponding sensory characteristics of the honey vary accordingly.

To determine the relative proportion of the chestnut component in each honey sample, we developed a mathematical equation based on the sensory and physicochemical characteristics of the various honeys. Electrical conductivity and free acids in the honeys were assessed following the harmonized methods of the International Honey Commission (Bogdanov et al. 1997). The electrical conductivity distinguishes chestnut nectar from floral nectar of other plants, such as Rubus spp., Tilia spp., or Rhododendron spp., while the level of free acids enables further discrimination of the chestnut component from honeydew components.

Sensory evaluation followed the standard approach in honey characterization (Gonnet and Vache 1985, 1992; Guyot et al. 1998; Piana et al. 2004; Castro-Vazquez et al. 2010). In particular, we determined the level of the main recognizable tastes such as chestnut, lime (Tilia spp.), other botanical sources (mixed flowers, mainly Rhododendron and Rubus spp.), and honeydew on a sevenpoint scale: 0 = absent, 1 = weak, 2 = weak-medium, $3=$ medium, $4=$ medium-strong, $5=$ strong, $6=$ exclusive. The relative contribution of chestnut to the overall sensory level (for short, RCS = Relative Chesnut Sensory) was then determined according to the following formula:

RCS $=$ chestnut sensory level / combined overall sensory levels (chestnut + lime + mixed flowers + honeydew $)$.

The C. sativa component (Csc) of the honey samples was then determined according to the formula:

$$
\text { Csc }=\text { Electrical conductivity / free acids * }(1+\mathrm{RCS})
$$

Chestnut honeys were classified as chestnut unifloral when the sensory level of C. sativa was maximal (6/6) and exclusive (no other detectable flavors, i.e., RCS $=1$, and chemical analysis revealed values meeting the Swiss honey classification standards (electrical conductivity $>0.86 \mathrm{mS} / \mathrm{cm}$; free acids $<22.4 \mathrm{meq} / \mathrm{kg}$; Bogdanov et al. 2008), which, in our case, corresponded to Csc values of $\geq 0.17$. Multifloral honeys containing other botanical sources in addition to chestnut were classified as having a moderate chestnut component when RCS $<1$ and Csc $\geq 0.10$, and a poor chestnut component when RCS $>0$ and Csc $<0.10$. As reported in Table 1 , due to the different forest compositions at the production sites, the beekeepers in the present 
study already produced honeys with different chestnut components before the ACGW arrival. In order to compare the yearly fluctuation in the Csc among beekeepers, we standardized the Csc values of each beekeeper with respect to its maximal Csc value using the following calculation (example for a single beekeeper):

$$
\text { Csc.loss }=1-\left[\left(\operatorname{Csc}-\mathrm{Csc}_{\max }\right) / \mathrm{Csc}_{\max } * 100\right]
$$

where $\mathrm{Csc}_{\max }$ stands for the highest Csc value in the beekeeper series under consideration (2010-2016).

Our preliminary tests show that melissopalynology (i.e., the branch of palynology that deals with the pollen contained in honey) is not suitable to discriminate between high and low amounts of chestnut components in honey, likely due to the fact that Castanea pollen is strongly over-represented in honey (Persano Oddo and Piro 2004, Yang et al. 2012).

\section{ACGW and T. sinensis Life History}

ACGW is a species native to China that accidentally arrived in Europe in 2002 (Brussino et al. 2002) where it became a significant pest for the European Chestnut tree (C. sativa). The adult wasp is $2.5-3 \mathrm{~mm}$ in length and has a black body with orange legs. Given that no male has been observed to date, the species is thelytokous, meaning that it produces fertile eggs by parthenogenesis. Generally in July, females lay between three to five eggs inside a chestnut bud and can lay up to 100 eggs in total (EPPO 2015). The total number of eggs laid per bud varies greatly from 1 to 176 (Panzavolta et al. 2012). Shortly after oviposition, larvae hatch from eggs but do not grow until the following spring when buds begin developing. It is at this time that larvae induce the formation of a variable number of galls differing in size, position (on a leaf, along the main shoot axis, on a stipule, or on a flower), and number of hosted larvae. Development is complete by July on emergence from galls.

The only natural enemy able to efficiently control its population is $T$. sinensis. Contrary to ACGW, T. sinensis adults emerge in spring from the previous year's withered galls and need to mate before laying a variable number of fertile eggs into the newly formed galls (Quacchia et al. 2008). Usually only one T. sinensis egg per ACGW larval chamber is laid. Soon after its oviposition, the egg hatches and the young larva feeds ectoparasitically on the ACGW larvae. It then pupates in autumn and completes its life cycle by the following spring (Quacchia et al. 2008).

\section{ACGW Damage Assessment}

An ACGW-monitoring program consisting of 18 sample sites (henceforth referred to as tree damage plots) was designed in 2010 in order to assess ACGW spread and incidence in the area, the year of arrival of $T$. sinensis, its efficiency in terms of parasitism, and related tree damage. During our study period (2010-2016), the overall ACGW damage level varied gradually from south to north as a function of the time of ACGW arrival. Specifically, this means that the damage level was similar within a 5 - $\mathrm{km}$ radius.

The sampling protocol was exactly the same in every tree damage plot. In each site, the number of mature chestnut trees sampled (mean height: $18 \mathrm{~m}$; standard deviation: $3.5 \mathrm{~m}$ ) varied depending on the heterogeneity of damage in the stand. Thus, 10 trees were sampled in 2010, 2011 (beginning of the epidemic), and 2016 (recovering stage), whereas between 2012 and 2015 (epidemic peak and the beginning of the recovery stage) the number of sampled trees was 15. To randomly select the trees, every year, 10 or 15 points were placed using the QGIS Random points tool (2016) on the corresponding tree damage plot map covering an area of approximately 10 hectares in total. Crown damage due to ACGW attack on the selected sampling trees was assessed during a 1-wk period in summer between mid-June and mid-July according to three distinct methods (at the same time). The first method consisted of visually assessing tree crown transparency following the Sanasilva approach (hereafter referred to as Sanasilva) as described by Müller and Stierlin (1990). The second method consisted of estimating the severity of ACGW damage by calculating the percentage of attacked buds with respect to available buds (Dk infestation $=$ no. of attacked buds/no. of total available buds) at shoot level (Kotobuki et al. 1985). For this purpose, 10 live shoots distributed over the entire tree crown were collected per sampled tree. These shoots, which correspond to the sprout from the previous vegetative seasons with respect to the sampling date (see Supplemental Material Fig. S1 for branch, shoot, and sprout examples), had average lengths of $5 \mathrm{~cm}$. The number of attacked buds (buds that grew and produced ACGW galls) and the number of total available buds (number of developed buds plus number of quiescent and dormant buds) were counted for analysis. The last method consisted in applying the damage composite index (DCI) proposed by Gehring et al. (2017) on one branch per tree. The DCI enables the assessment of current and past year's damage endured by the tree and is computed on branches of at least half a meter in length that contain a minimum of 10 shoots. Briefly, the branch analysis consisted in counting the average number of galls on shoots ( $g$; representing the current year's damage), the proportion between living and dead shoots $(d$; representing the previous year's damage), and the proportion between live shoots and reactivated dormant buds ( $r$; buds that started growing mainly because of stress). The DCI is then calculated using the following formula: DCI $=(g * 0.120+d * 0.479+r * 0.525) * 100$ (see Gehring et al. 2017 for details). For both methods (Dk infestation and DCI), shoots and branches were collected using a long tree pruner (up to $8 \mathrm{~m}$ in length) and by climbing to the top of the tree using treeclimbing techniques.

Finally, the presence of $T$. sinensis and the degree of D. kuriphilus parasitism $(\mathrm{Ts} \%=$ (no. of live T. sinensis) $/($ no. of D. kuriphilus chambers) * 100) (Quacchia et al. 2014) were verified at each site by collecting up to 200 galls per site from the previously selected branches and dissecting them.

In order to assess possible relationships between ACGW impact and the chestnut component in the related honey, a tree damage plot from our monitoring program was associated to each of the selected honey production sites based on its geographical area (Fig. 1).

\section{Honeybee Foraging Behavior and Meteorological Data}

In our study area, the selected beehives are located inside or close to the forest in which foragers can find all the nectar and pollen of tree species present in the analyzed honey (Table 1). According to Seeley (1986), in honeybee colonies, foragers typically fly distances as short as possible while focusing on abundant, nectar-rich sources. It is known that the chestnut tree represents one of the best nectar and pollen sources for bees (Maurizio and Schaper 1994, Persano Oddo and Pirro 2004, Aronne et al. 2012, Yang et al. 2012). It is thus reasonable to assume that in our study area foragers do not fly far away and are able to find all the necessary pollen and nectar within an area of a $5-\mathrm{km}$ radius.

Moreover, the foraging activities of honeybees are also influenced by many weather factors such as temperature, wind velocity, relative humidity and precipitation, as well as the time of the 
day (see Abou-Shaara 2014 for a review). In order to consider the possible role of weather conditions during the chestnut tree flowering season in our analysis, we selected the nearest available meteorological station to be associated with each honey production site. These, together with the associated tree damage plots appear linked together in Fig. 1.

Weather data from 2010 to 2016 (at a resolution of 10-min intervals) were downloaded from the OASI website (Osservatorio Ambientale della Svizzera Italiana; http://www.oasi.ti.ch, accessed 5 December 2017). We retained only data referring to the flowering period of the considered species in the honey sensory analysis (i.e., C. sativa, Tilia spp., Rhododendron spp., and Rubus spp.), specifically, from 1 June to 1 August (http://www.meteoswiss.admin.ch, accessed 5 December 2017) and only for daylight hours which cover potential bee foraging activity. Seasonal mean temperature $\left({ }^{\circ} \mathrm{C}\right)$, seasonal mean wind speed (meters per second; $\mathrm{m} / \mathrm{s}$ ), seasonal mean relative humidity $(\%)$, seasonal sum of precipitation $(\mathrm{mm})$, and bee flying time were also retained as potential explanatory variables (see details in Table 2 and Supplemental Material Fig. S2).

\section{Statistical Analysis}

The relationship between the Csc with the three different ACGWinduced damage indices (i.e., Dk infestation, Sanasilva, and DCI) and weather parameters (Table 2) was first inspected separately by means of a univariate comparative analysis and tested for correlation issues (Pearson $R>0.5$ ) among variables. A linear mixedeffects regression approach was then used to analyze the effects of ACGW damage and weather conditions (explanatory variables) on the Csc variation (response variable) between 2010 and 2016. For the contiguous sites, VO1 and VO2, only one meteorological station was available. Therefore, the corresponding Csc- and ACGWinduced damage index values were averaged and the resulting mean values were then related to the meteorological data.

The random configuration of the mixed-effects model (between random intercept or random intercept and slope) was set according to the procedure described in Zuur et al. (2009). Model selection was made on the basis of the $\mathrm{AIC}_{\mathrm{c}}$ coefficient (Akaike information criterion with a second-order correction for small sample size) and goodness of fit evaluated using pseudo $R^{2}$ (Nakagawa and Schielzeth 2013, Johnson 2014, Jaeger et al. 2017). Model assumptions were checked with residual plots, and only those that showed no obvious deviations from normality or homoscedasticity were considered.

Specifically, two different sets of models were run. The first set included three different models, with every single ACGW-induced damage index as an explanatory variable, each run in turn in order to select the one most related to Csc. As random effects, we had intercepts for beekeeper as well as by-beekeeper random slopes for the effect of the different ACGW-induced damage indices.

Forward model selection was then used to test the additional explanatory power provided by each weather parameter with respect to the previous best model with a single damage index, i.e., $\mathrm{Csc} \sim$ best ACGW-induced damage index + weather parameters + random terms.

In the second step, possible ACGW-induced damage index (Dk infestation, Sanasilva, or DCI) thresholds causing significant Csc. loss that were retained in the best model were tested using MannWhitney $U$ tests (Wilcoxon rank-sum tests) in a univariate comparative analysis (with significant differences at $P<0.05$ ).

All analyses were performed in $R$ (version 3.3.3; $R$ Core Team 2017). Linear mixed-effects models were fit using the lme 4 package (Bates et al. 2015) and their goodness of fit evaluated with the r.squaredGLMM function of the MuMIn package (Barton 2016).

\section{Results}

The sampled honeys ranged from unifloral to chestnut-poor honey. Only two beekeepers (MA1 and BE1) had a chestnut-rich environment enabling them to potentially produce unifloral chestnut honey. MA1 produced unifloral chestnut honey again in 2016, that is, in the second year after biological control was achieved by $T$. sinensis (Table 3). GO1, in contrast, is located in a marginal chestnut site and only has the potential to produce honey with a rather low chestnut component, as was the case even before the ACGW epidemic. In contrast, all other considered beekeepers were located in an intermediate environment that allowed the potential production of honey with a moderate chestnut component (Table 3). During the peak of the epidemic occurring between 2012 and 2014 (see Dk infestation in Table 3), the chestnut component in honey reached minimum values within each beekeeper series.

The best random factor configuration for the modeling approach was represented by random intercepts for beekeeper as well as bybeekeeper random slopes for the Dk infestation effect.

The best linear mixed-effects model considering only the ACGWinduced damage index retained $\mathrm{Dk}$ infestation as the best explanatory variable (negatively related to the Csc-see Table 4) with a conditional $R^{2}\left(R^{2} \mathrm{c}\right)$ of 0.80 . Since the addition of weather variables resulted in minimal gains in $R^{2} \mathrm{c}$ and did not significantly improve the ACGW-induced damage index model (Table 4), we identified the model including $\mathrm{Dk}$ infestation only as the best parsimonious model (Fig. 2).

Table 2. Main weather parameters considered in the analysis influencing bee foraging activity (BFA) and chestnut growth (CG)

\begin{tabular}{llll}
\hline \multicolumn{1}{c}{ Parameter } & Unit & Notes \\
\hline BFA $^{a}$ & Precipitation & $\mathrm{mm}$ & Sum \\
& Relative humidity & $\%$ & Average \\
& Temperature & ${ }^{\circ} \mathrm{C}$ & Average \\
& Wind speed & $\mathrm{m} / \mathrm{s}$ & Average \\
& Bee fly time & $\mathrm{h}$ & Sum of hours with dry weather. For calculations, we considered 1 h with no precipitation as the min- \\
& & imum time for a relevant foraging activity. Because raw data was at 10 -min intervals, we considered \\
& & prop & Proportion between bee fly time during the peak of chestnut blooming (15 June to 15 July) and bee fly \\
& & & time during the whole period considered (1 June to 1 August)
\end{tabular}

${ }^{a}$ Weather data considered from the 1 June to 1 August and for daylight hours, i.e., covering potential bee foraging activity.

${ }^{b}$ Weather data considered only during the month of May and over a full $24 \mathrm{~h}$. 
Table 3. Tree damage, honey composition, and chestnut pollen content by beekeeper since 2010

\begin{tabular}{|c|c|c|c|c|c|c|c|c|c|c|c|c|c|c|}
\hline \multirow[b]{3}{*}{ Beekeeper ID } & \multirow[b]{3}{*}{ Year } & \multicolumn{4}{|c|}{ Tree damage plot } & \multicolumn{2}{|c|}{$\begin{array}{l}\text { Physicochemical } \\
\text { analysis }\end{array}$} & \multicolumn{4}{|c|}{ Sensory analysis } & \multirow{3}{*}{$\begin{array}{c}\text { C. sativa } \\
\text { component }^{b}\end{array}$} & \multirow{3}{*}{$\frac{\text { Honey }^{c}}{\text { Type }}$} & \multirow{3}{*}{$\begin{array}{c}\text { Honey } \\
\text { composition }^{d}\end{array}$} \\
\hline & & \multicolumn{4}{|c|}{$\begin{array}{l}\text { Dk } \\
\text { infestation Sanasilva DCI Ts\% }\end{array}$} & \multirow{2}{*}{$\frac{\begin{array}{c}\text { Electrical } \\
\text { conductivity }\end{array}}{\mathrm{mS} / \mathrm{cm}}$} & \multirow{2}{*}{$\begin{array}{c}\begin{array}{c}\text { Free } \\
\text { acids }\end{array} \\
\text { meq/kg }\end{array}$} & \multirow{2}{*}{$\begin{array}{c}\text { Castanea } \\
\text { sativa } \\
\end{array}$} & \multicolumn{3}{|c|}{$\begin{array}{l}\text { Tilia Mixed } \\
\text { spp. flowers }{ }^{a} \text { Honeydews }\end{array}$} & & & \\
\hline & & $\%$ & $\%$ & & $\%$ & & & & & re $(0-6)^{e}$ & & & & \\
\hline \multirow[t]{7}{*}{ VM1 } & 2010 & 15 & 10 & 2 & 0 & 1.07 & 9.99 & 5 & 2 & 0 & 0 & 0.18 & $\mathrm{M}$ & $\mathrm{Cs} / \mathrm{Ti}$ \\
\hline & 2011 & 30 & 35 & 5 & 0 & 1.14 & 18.62 & 4 & 0 & 2 & 2 & 0.09 & $\mathrm{P}$ & $\mathrm{Cs} / \mathrm{Mf} / \mathrm{Hd}$ \\
\hline & 2012 & 35 & 40 & 15 & 2 & 0.87 & 16.96 & 2 & 1 & 4 & 2 & 0.06 & $\mathrm{P}$ & $\mathrm{Mf} / \mathrm{Cs} / \mathrm{Hd} / \mathrm{Ti}$ \\
\hline & 2013 & 32 & 46 & 20 & 4 & 0.62 & 16.59 & 0 & 4 & 2 & 0 & 0.04 & & $\mathrm{Ti} / \mathrm{Mf}$ \\
\hline & 2014 & 46 & 55 & 19 & 74 & 0.78 & 27.90 & 1 & 1 & 4 & 0 & 0.03 & $\mathrm{P}$ & $\mathrm{Mf} / \mathrm{Cs} / \mathrm{Ti}$ \\
\hline & 2015 & 14 & 32 & 15 & 48 & 1.19 & 16.44 & 4 & 0 & 2 & 0 & 0.12 & M & $\mathrm{Cs} / \mathrm{Mf}$ \\
\hline & 2016 & 7 & 17 & 0 & 55 & 1.50 & 16.28 & 3 & 0 & 2 & 0 & 0.15 & $\mathrm{M}$ & $\mathrm{Cs} / \mathrm{Mf}$ \\
\hline \multirow[t]{7}{*}{ MA1 } & 2010 & 10 & 15 & 0 & 0 & 0.97 & 11.70 & 4 & 2 & 2 & 0 & 0.12 & $\mathrm{M}$ & $\mathrm{Cs} / \mathrm{Ti} / \mathrm{Mf}$ \\
\hline & 2011 & 38 & 30 & 2 & 0 & 1.39 & 16.82 & 6 & 0 & 0 & 0 & 0.17 & $\mathrm{U}$ & Cs \\
\hline & 2012 & 45 & 45 & 10 & 1 & 0.97 & 9.65 & 4 & 4 & 2 & 0 & 0.14 & $\mathrm{M}$ & $\mathrm{Cs} / \mathrm{Ti} / \mathrm{Mf}$ \\
\hline & 2013 & 42 & 51 & 22 & 20 & 0.77 & 11.20 & 0 & 4 & 2 & 0 & 0.07 & & $\mathrm{Ti} / \mathrm{Mf}$ \\
\hline & 2014 & 26 & 68 & 7 & 69 & 1.36 & 21.95 & 6 & 0 & 0 & 4 & 0.10 & M & $\mathrm{Cs} / \mathrm{Hd}$ \\
\hline & 2015 & 21 & 39 & 10 & 85 & 1.26 & 11.63 & 4 & 0 & 3 & 0 & 0.17 & $\mathrm{M}$ & $\mathrm{Cs} / \mathrm{Mf}$ \\
\hline & 2016 & 8 & 22 & 0 & 64 & 1.64 & 9.12 & 6 & 0 & 0 & 0 & 0.36 & $\mathrm{U}$ & Cs \\
\hline \multirow[t]{7}{*}{ BE1 } & 2010 & 0 & 0 & 0 & 0 & & & & & & & & & \\
\hline & 2011 & 15 & 20 & 1 & 0 & 1.43 & 14.71 & 6 & 0 & 0 & 0 & 0.19 & $\mathrm{U}$ & Cs \\
\hline & 2012 & 52 & 55 & 1 & 2 & 0.72 & 9.78 & 0 & 4 & 2 & 0 & 0.07 & & Ti/Mf \\
\hline & 2013 & 53 & 57 & 22 & 2 & & & & & & & & & \\
\hline & 2014 & 55 & 55 & 18 & 36 & 0.89 & 19.45 & 0 & 4 & 4 & 0 & 0.05 & & $\mathrm{Ti} / \mathrm{Mf}$ \\
\hline & 2015 & 48 & 33 & 10 & 88 & 0.87 & 15.30 & 1 & 2 & 4 & 0 & 0.06 & $\mathrm{P}$ & $\mathrm{Mf} / \mathrm{Ti} / \mathrm{Cs}$ \\
\hline & 2016 & 9 & 32 & 0 & 93 & 0.92 & 13.86 & 0 & 4 & 3 & 0 & 0.07 & & Ti/Mf \\
\hline \multirow[t]{7}{*}{ VO1 } & 2010 & 0 & 0 & 0 & 0 & 0.86 & 13.27 & 1 & 0 & 4 & 0 & 0.08 & $\mathrm{P}$ & Mf/Cs \\
\hline & 2011 & 7 & 10 & 0 & 0 & 1.38 & 11.12 & 4 & 0 & 4 & 0 & 0.19 & $\mathrm{M}$ & $\mathrm{Cs} / \mathrm{Mf}$ \\
\hline & 2012 & 36 & 35 & 3 & 3 & 0.75 & 10.13 & 0 & 6 & 0 & 0 & 0.07 & & $\mathrm{Ti}$ \\
\hline & 2013 & 30 & 45 & 25 & 3 & 0.96 & 14.96 & 1 & 2 & 4 & 0 & 0.07 & $\mathrm{P}$ & $\mathrm{Mf} / \mathrm{Ti} / \mathrm{Cs}$ \\
\hline & 2014 & 44 & 44 & 35 & 38 & 1.06 & 19.28 & 1 & 0 & 2 & 4 & 0.06 & $\mathrm{P}$ & $\mathrm{Hd} / \mathrm{Mf} / \mathrm{Cs}$ \\
\hline & 2015 & 33 & 58 & 19 & 85 & 0.76 & 9.95 & 2 & 6 & 2 & 0 & 0.09 & $\mathrm{P}$ & Ti/Cs/Mf \\
\hline & 2016 & 21 & 35 & 0 & 83 & 1.17 & 10.22 & 4 & 0 & 4 & 0 & 0.17 & $\mathrm{M}$ & $\mathrm{Cs} / \mathrm{Mf}$ \\
\hline \multirow[t]{7}{*}{ VO2 } & 2010 & 0 & 0 & 0 & 0 & 1.44 & 11.55 & 4 & 0 & 2 & 2 & 0.25 & $\mathrm{M}$ & $\mathrm{Cs} / \mathrm{Mf} / \mathrm{Hd}$ \\
\hline & 2011 & 7 & 10 & 0 & 0 & & & & & & & & & \\
\hline & 2012 & 36 & 35 & 3 & 3 & 0.75 & 9.04 & 1 & 4 & 2 & 0 & 0.09 & $\mathrm{P}$ & $\mathrm{Ti} / \mathrm{Mf} / \mathrm{Cs}$ \\
\hline & 2013 & 30 & 45 & 25 & 3 & 0.92 & 13.21 & 1 & 6 & 0 & 0 & 0.08 & $\mathrm{P}$ & $\mathrm{Cs} / \mathrm{Ti}$ \\
\hline & 2014 & 44 & 44 & 35 & 38 & 1.25 & 22.14 & 2 & 0 & 4 & 2 & 0.07 & $\mathrm{P}$ & Mf/Cs/Hd \\
\hline & 2015 & 33 & 58 & 19 & 85 & 0.94 & 10.68 & 3 & 4 & 4 & 0 & 0.11 & $\mathrm{M}$ & Ti/Mf/Cs \\
\hline & 2016 & 21 & 35 & 0 & 83 & 1.10 & 12.36 & 1 & 0 & 5 & 0 & 0.10 & $\mathrm{M}$ & $\mathrm{Mf} / \mathrm{Cs}$ \\
\hline \multirow[t]{7}{*}{ GO1 } & 2010 & 0 & 0 & 0 & 0 & 0.79 & 17.49 & 2 & 2 & 2 & 0 & 0.06 & $\mathrm{P}$ & $\mathrm{Cs} / \mathrm{Ti} / \mathrm{Mf}$ \\
\hline & 2011 & 0 & 0 & 0 & 0 & 0.83 & 19.68 & 2 & 0 & 2 & 2 & 0.06 & $\mathrm{P}$ & $\mathrm{Cs} / \mathrm{Mf} / \mathrm{Hd}$ \\
\hline & 2012 & 20 & 20 & 1 & 3 & 0.66 & 14.01 & 0 & 4 & 2 & 0 & 0.05 & & Ti/Mf \\
\hline & 2013 & 35 & 41 & 22 & 10 & 0.61 & 17.83 & 0 & 0 & 4 & 0 & 0.03 & & Mf \\
\hline & 2014 & 45 & 62 & 5 & 61 & 0.69 & 17.00 & 0 & 2 & 2 & 0 & 0.04 & & Ti/Mf \\
\hline & 2015 & 29 & 38 & 4 & 87 & 0.75 & 24.4 & 0 & 1 & 6 & 0 & 0.03 & & $\mathrm{Mf} / \mathrm{Ti}$ \\
\hline & 2016 & 14 & 38 & 0 & 81 & 0.85 & 18.00 & 0 & 4 & 2 & 0 & 0.05 & & Ti/Mf \\
\hline
\end{tabular}

${ }^{a}$ Mixed flowers $(M f)=$ other botanical origin, mainly Rhododendron spp. and Rubus spp.

${ }^{b}$ C. sativa component $(\mathrm{Csc})=$ electrical conductivity/free acids $*(1+\mathrm{RCS}) . \mathrm{RCS}=$ chestnut sensory level/cumulated overall sensory levels $($ chestnut + lime + mixed flowers + honeydew).

${ }^{c}$ Unifloral $(\mathrm{U})=$ electrical conductivity $>0.86 \mathrm{mS} / \mathrm{cm}$, free acids $<22.4 \mathrm{meq} / \mathrm{kg}$ and sensory level of Castanea sativa is maximal and exclusive $(\mathrm{RCS}=1) ; \mathrm{Moderate}$ $(\mathrm{M})=\mathrm{RCS}<1$ and $\mathrm{Csc} \geq 0.10$; Poor $(\mathrm{P})=$ RCS $>0$ and Csc values $<0.10$.

${ }^{d} \mathrm{Cs}=$ Castanea sativa, $\mathrm{Ti}=$ Tilia spp., Mf = Mixed flowers, $\mathrm{Hd}=$ Honeydews.

${ }^{e}$ Score: 0 = absent, 1 = weak, 2 = weak-medium, 3 = medium, 4 = medium-strong, 5 = strong, 6 = exclusive.

Fig. 3 shows the relationship between the relative decrease in the chestnut component in honey within each beekeeper series (Csc. loss $=$ C. sativa component loss) and the Dk infestation. Significant increases in Csc.loss are detectable starting from an average $\mathrm{Dk}$ infestation of $30 \%$, whereas more than half of the chestnut component is lost in nearly all the honey samples when the Dk infestation exceeds $40 \%$ (Fig. 3). Fig. S3 in the Supplemental Material gives a visual impression of the tree crown habit of the damage categories represented in Fig. 3.

Considering the average value of all beekeepers by year, the evolution of the Csc.loss as well as the relative chestnut contribution to the overall sensory-level analysis (for short, RCS = Relative Chestnut Sensory) follows the ACGW epidemic trend (Fig. 4). This is shown in the progressive decrease in the chestnut component in honey (Csc. 
Table 4. Best linear mixed-effects regression models according to $\mathrm{AIC}_{\mathrm{c}}$ ranking considering all variables, or separately with tree damage due to Dryocosmus kuriphilus attack and weather variables

\begin{tabular}{|c|c|c|c|c|c|c|c|}
\hline & Model formula & Fixed effect & Estimate $(95 \% \mathrm{CI})$ & $\mathrm{S}_{\text {resid }}$ & $t$ value & $\mathrm{AIC}_{\mathrm{C}}$ & $R^{2} \mathrm{c}$ \\
\hline \multirow{6}{*}{$\begin{array}{l}\text { Tree damage } \\
\text { only }\end{array}$} & \multirow[t]{2}{*}{${ }^{a} \mathrm{Csc} \sim \mathrm{Dk}$ inf $+r$} & Intercept & $0.165[0.102,0.229]$ & 0.027 & 6.22 & \multirow[t]{2}{*}{-115.53} & \multirow[t]{2}{*}{0.80} \\
\hline & & Dk inf & $-0.002[-0.003,-0.001]$ & 0.000 & -5.12 & & \\
\hline & \multirow[t]{2}{*}{ Csc $\sim$ Sanasilva $+r$} & Intercept & $0.174[0.104,0.249]$ & 0.030 & 5.78 & \multirow[t]{2}{*}{-104.26} & \multirow[t]{2}{*}{0.73} \\
\hline & & Sanasilva & $-0.002[-0.003,-0.001]$ & 0.001 & -3.78 & & \\
\hline & \multirow[t]{2}{*}{$\mathrm{Csc} \sim \mathrm{DCI}+r$} & Intercept & $0.131[0.083,0.180]$ & 0.020 & 6.53 & \multirow[t]{2}{*}{-100.01} & \multirow[t]{2}{*}{0.63} \\
\hline & & DCI & $-0.003[-0.006,-0.001]$ & 0.001 & -3.39 & & \\
\hline \multirow{12}{*}{$\begin{array}{l}\text { With weather } \\
\text { variables }\end{array}$} & \multirow[t]{3}{*}{$\mathrm{Csc} \sim \mathrm{Dk}$ inf $+\mathrm{P}+r$} & Intercept & $0.157[0.092,0.223]$ & 0.028 & 5.52 & \multirow[t]{3}{*}{-112.88} & \multirow[t]{3}{*}{0.80} \\
\hline & & Dk inf & $-0.002[-0.003,-0.001]$ & 0.000 & -4.89 & & \\
\hline & & $\mathrm{P}$ & $0.000[0.000,0.000]$ & 0.000 & 0.78 & & \\
\hline & \multirow[t]{3}{*}{ Csc $\sim$ Dk inf $+T+r$} & Intercept & $0.244[0.089,0.406]$ & 0.076 & 3.21 & \multirow[t]{3}{*}{-113.45} & \multirow[t]{3}{*}{0.82} \\
\hline & & Dk inf & $-0.002[-0.003,-0.001]$ & 0.000 & -5.09 & & \\
\hline & & $T$ & $-0.003[-0.010,-0.003]$ & 0.003 & -1.12 & & \\
\hline & \multirow[t]{3}{*}{$\mathrm{Csc} \sim \mathrm{Dk}$ inf $+\mathrm{WS}+r$} & Intercept & $0.246[0.114,0.380]$ & 0.065 & 3.82 & \multirow[t]{3}{*}{-114.06} & \multirow[t]{3}{*}{0.82} \\
\hline & & Dk inf & $-0.002[-0.003,-0.001]$ & 0.000 & -4.98 & & \\
\hline & & WS & $-0.044[-0.108,-0.022]$ & 0.031 & -1.4 & & \\
\hline & \multirow[t]{3}{*}{$\mathrm{Csc} \sim \mathrm{Dk} \inf +\mathrm{RH}+r$} & Intercept & $0.146[-0.048,0.318]$ & 0.084 & 1.74 & \multirow[t]{3}{*}{-112.34} & \multirow[t]{3}{*}{0.80} \\
\hline & & Dk inf & $-0.002[-0.003,-0.001]$ & 0.000 & -5.18 & & \\
\hline & & $\mathrm{RH}$ & $0.000[-0.002,0.003]$ & 0.001 & 0.24 & & \\
\hline
\end{tabular}

95\% CI = confidence interval; $\mathrm{AIC}_{\mathrm{c}}=$ Akaike Information Criterion with a second-order correction for small sample size; Csc = Castanea sativa component; Dk inf = Dk infestation (\%); $\mathrm{P}=$ precipitation $(\mathrm{mm}) ; r=$ random factors; $R^{2} \mathrm{c}=$ conditional $R^{2}$ showing the variance explained by the entire model (fixed and random factors); $\mathrm{RH}=$ relative humidity $(\%) ; T=$ temperature $\left({ }^{\circ} \mathrm{C}\right) ; \mathrm{WS}=$ wind speed $(\mathrm{m} / \mathrm{s})$.

${ }^{a}$ Best model considering all variables (tree damage and weather variables). Please note that because it retained only Dk infestation, the model has been placed in the table under the "Tree damage only" section.

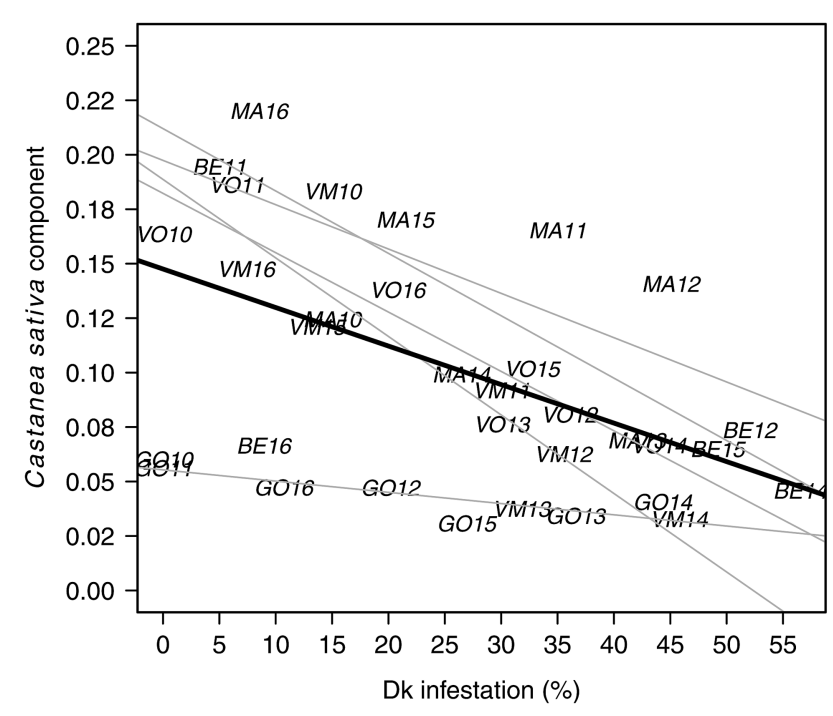

Fig. 2. Variation in the Castanea sativa component in honey due to Dryocosmus kuriphilus infestation as predicted by linear mixed-effects models. The black line shows the fitted values for the overall model (the predicted average variations across beekeeper), whereas gray lines represent the effect for each beekeeper as obtained by adding intercept and slope adjustments to the overall model fit. Codes are composed of the Beekeeper-ID and the abbreviated year. For the contiguous sites, VO1 and VO2 only one meteorological station was available. Consequently, mean values were calculated at the VO site for the $C$. sativa component and the ACGW-induced damage. Csc (C. sativa component) = electric conductivity/ free acid $*(1+$ RCS). RCS (relative contribution of chestnut to the overall sensory level) $=$ chestnut sensory level/cumulated overall sensory levels (chestnut + lime + mixed flowers + honeydew). Dk infestation (D. kuriphilus infestation $)=$ no. attacked buds/no. total available buds $* 100$.

loss) until the Dk infestation peaked in 2014 and its recovery to almost the same average values as in 2010 during the subsequent chestnut resurgence phase (Fig. 4).

\section{Discussion}

Honey characteristics strongly depend on vegetation and on the abundance and flowering phenology of the polleniferous and nectariferous plants surrounding the apiaries. Several studies document this for different ecosystems and at different spatial scales (Odoux et al. 2012, Bagella et al. 2013) and for chestnut ecosystems in different geographic contexts (Castro-Vázquez et al. 2010, Yang et al. 2012). Flowering phenology and honeybee activities in flower visiting, pollinating, and food-storing may also vary as a function of weather conditions (Gerlach 1985, Blaschon et al. 1999, Crailsheim et al. 1999, Tuell and Isaacs 2010). In this study, we show how honey composition may also become altered as a consequence of a pestinduced multiannual impact on a widely present pollen-producing forest tree species.

Our results highlight how severe and repeated ACGW damage to chestnut trees has induced a corresponding loss of the chestnut component in honey, especially during the peak of the epidemic that clearly overwhelmed and masked any possible effect of changing weather conditions during the chestnut flowering periods. Among chestnut damage indices, Dk infestation was found to be the most suitable for predicting variation in Csc. The Sanasilva index behaves similarly to the Dk infestation, whereas the DCI was found to be less suitable although following similar trends. As described in Gehring et al. (2017), when biological control through T. sinensis takes effect and chestnut tree recovery begins, the process starts from the branch apex producing ACGW-free shoots from healthy, flower-producing terminal buds. Such a recovery process is best described by the Dk infestation and the Sanasilva indices. Both proxies were found to be very sensitive to the damage and recovery of the external, lightexposed crown parts that bear the nectariferous catkins on sprout (new shoot growth). The Sanasilva index, however, places more emphasis on existing gaps in the external crown due to dead shoots, whereas the DCI considers the entire branch architecture, thus exaggerating the importance of missing internal lateral branches with respect to the potential flower production of trees. 


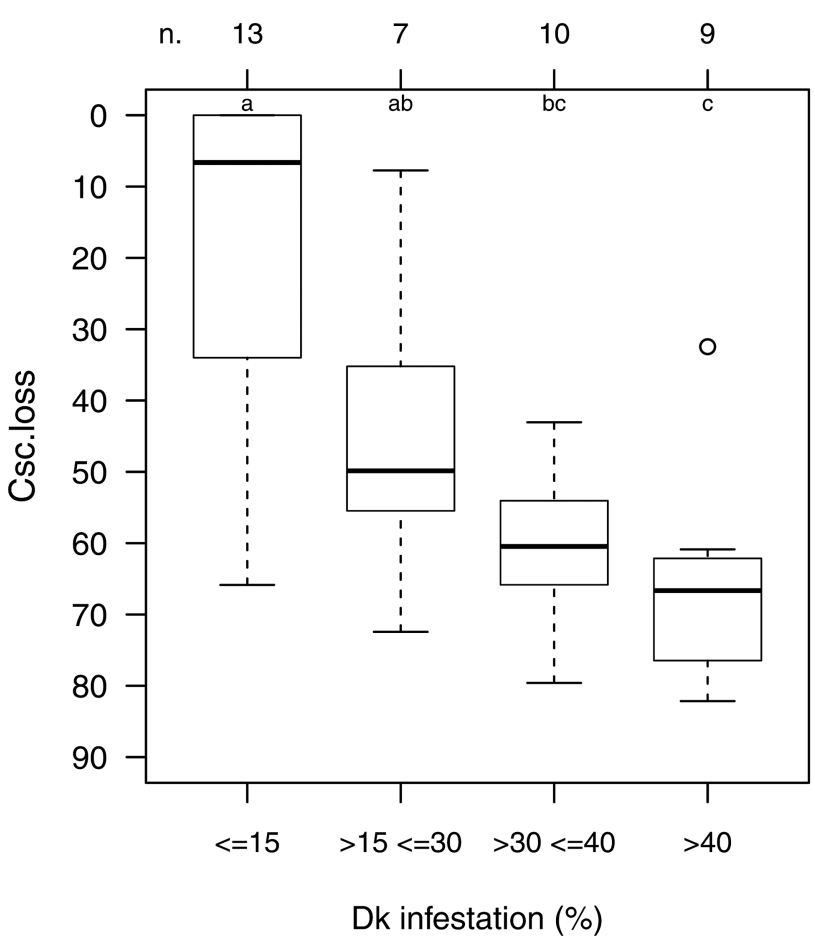

Fig. 3. Castanea sativa component loss in honey as a function Dryocosmus kuriphilus infestation. Different letters indicate significant differences at $P$ $<0.05$ (nonparametric Mann-Whitney $U$ test with Holm's adjustment). Csc. loss $(C$. sativa component loss $)=1-\left(\left(\mathrm{Csc}-\mathrm{Csc}_{\max }\right) / \mathrm{Csc}_{\max } * 100\right)$, where $\mathrm{Csc}_{\max }$ stands for the highest Csc value within the beekeeper series under consideration 2010-2016. Dk infestation (D. kuriphilus infestation) $=$ no. attacked buds/no. total available buds * 100 .

Decreases in the chestnut component in honey became statistically significant starting from an infestation of $30 \%$ (Dk infestation). When Dk infestation reaches $40 \%$, the production of unifloral chestnut honey or honey with a moderate chestnut component becomes difficult in the study area. As soon as chestnut tree damage decreased, within $2 \mathrm{yr}$ the chestnut component in honey returned to almost the same values as before the epidemic (2010). The only exception was at site BE1, which experienced the opposite behavior with a relatively low chestnut component despite a strong recovery in the damage indices. This may be due to possible additional noise in the data as a consequence of local and episodic disturbances, such as hale events followed by heavy chestnut blight attacks in the tree crowns (Rigling et al. 2014).

ACGW-induced temporary reduction in chestnut pollen and nectar availability resulted in a shift in honeybee foraging to the few phenologically synchronous nectariferous species that were available, such as Tilia spp., Rhododendron spp., Rubus spp., as well as honeydew. Such a shift, which is occasional and fluctuating according to the timing and weather conditions during a normal season of chestnut flowering, may become practically a requirement when chestnut flowering is lacking as a consequence of the severe ACGW attacks.

Meteorological variables showed very low correlations with the decrease in the chestnut component in honey during our study period. Although some fluctuations occurred during the period in question, they did not appear to be directly related to the Csc trend. Moreover, meteorological variables did not significantly improve the best model in terms of $\mathrm{AIC}_{c}$ or explained variance.

From a methodological point of view, the proposed combined chemical-analytical and sensory approach and the related

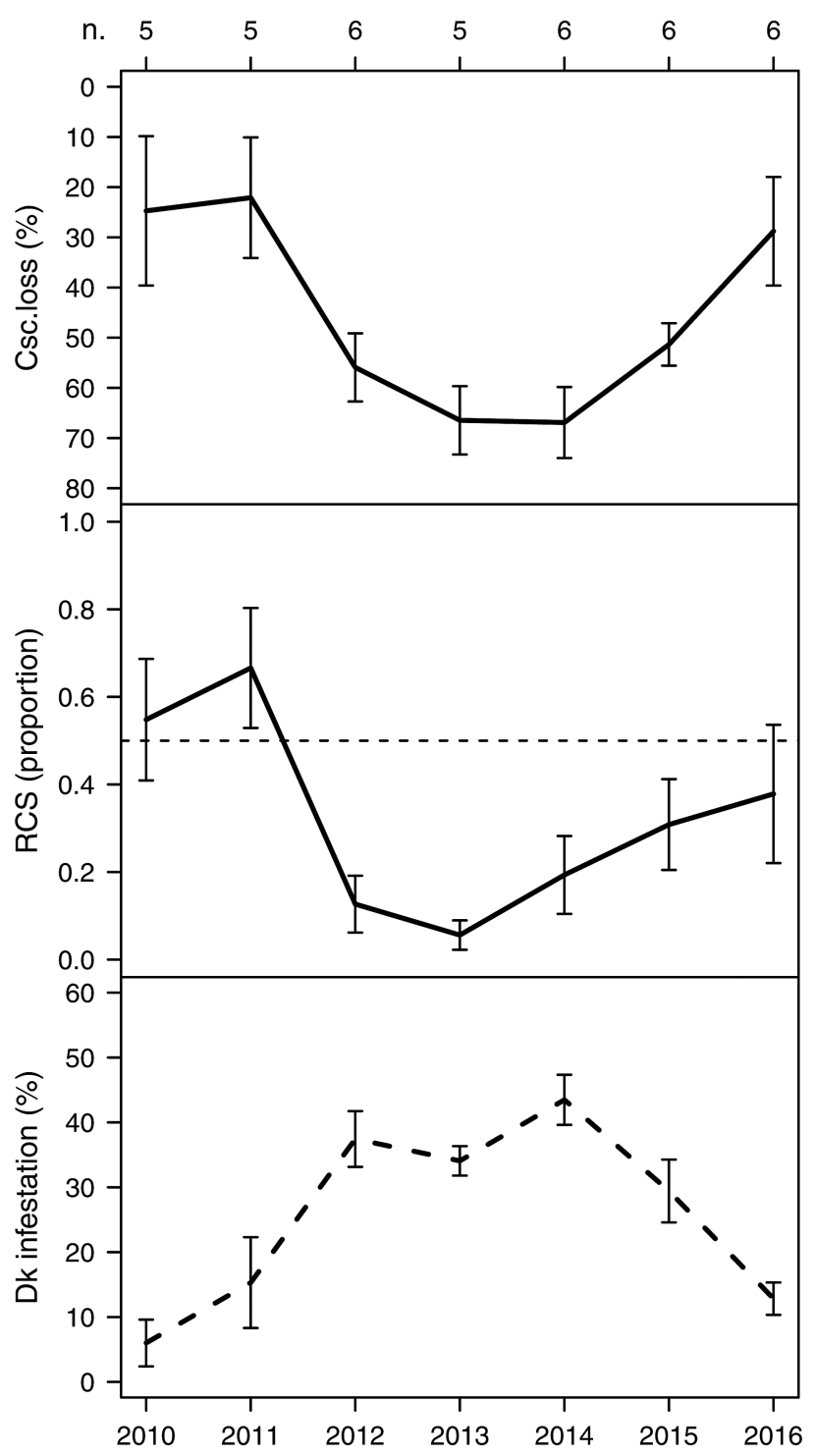

Fig. 4. Yearly evolution of Castanea sativa component loss in honey, average relative chestnut contribution to the overall sensory analysis, and Dk infestation. Average $C$. sativa component loss (Csc.loss; solid line, top plot), average relative chestnut contribution to the overall sensory-level analysis (RCS; solid line, center plot) and Dryocosmus kuriphilus infestation (dashed line, bottom plot). Vertical bars $=95 \%$ confidence interval. Csc.loss (C. sativa component loss $)=1-\left(\left(\mathrm{Csc}-\mathrm{Csc}_{\max }\right) / \mathrm{Csc}_{\max } * 100\right)$, where $\mathrm{Csc}_{\max }$ stands for the highest Csc value in the beekeeper series under consideration 2010-2016. RCS (relative contribution of chestnut to the overall sensory level) $=$ chestnut sensory level/cumulated overall sensory levels (chestnut + lime + mixed flowers + honeydew). Dk infestation $(D$. kuriphilus infestation $)=$ no. attacked buds/no. total available buds * 100 .

mathematical equations were found to be a highly suitable method for assessing the chestnut component in honey samples and its evolution over time. In our specific case, a palynological approach alone based on pollen count would likely be insufficient, due to the general overrepresentation of Castanea pollen in honey with a traceable chestnut component (Persano Oddo et al. 1995) induced by the conspicuous pollen production of male catkins where nectar is also located. When looking for nectar, bees easily take large amounts of the small pollen grains together with the nectar, which always makes it strongly over-represented in honey. 


\section{Conclusions}

The present study highlights the possible far-reaching effects of the damage caused by the accidental introduction of an exotic pest into the chestnut forest ecosystems of the southern Alps. As postulated by Quacchia et al. (2014) for Piedmont, the successful and timely control of the ACGW by its specific natural enemy Torymus sinensis appears to enable, with time, the almost full recovery of tree crowns. It seems, therefore, reasonable to predict for the near future the normalization of chestnut honey production in the study area, following the trend registered in our study starting in 2015 .

\section{Supplementary Material}

Supplementary data are available at Journal of Economic Entomology online.

\section{Acknowledgments}

We would like to thank the beekeepers for providing their honey for the sensory and chemical analysis and Nikos Koutsias for statistical advice. Data collection regarding the tree damage assessment was partially funded by the Forest Service of Canton Ticino and Federal Office for the Environment FOEN. This study did not receive any other specific grant from funding agencies in the public, commercial, or not-for-profit sectors.

\section{Conflict of Interest}

The authors declare that they have no conflicts of interest.

\section{References Cited}

Abou-Shaara, H. F. 2014. The foraging behaviour of honey bees, Apis mellifera: a review. Vet. Med. 59: 1-10.

Aebi, A., K. Schonrogge, G. Melika, A. Alma, G. Bosio, A. Quacchia, L. Picciau, Y. Abe, S. Moriya, K. Yara, et al. 2006. Parasitoid recruitment to the globally invasive chestnut gall wasp Dryocosmus kuriphilus. In: Ozaki, K., Yukawa, J., Ohgushi, T., Price, P.W. (eds) Galling Arthropods and Their Associates. Springer, Tokyo.

Apisuisse. 2015. Gli svizzeri amano il loro miele. Press release May 2015. http://www.tio.ch/News/Ticino/Attualita/1032842/Gli-svizzeri-amanoil-loro-miele-in-Ticino-quello-di-castagno--/ (accessed 5 December 2017).

Aronne, G., and V. De Micco. 2010. Traditional melissopalynology integrated by multivariate analysis and sampling methods to improve botanical and geographical characterisation of honeys. Plant Biosyst. 144: 833-840.

Aronne, G., M. Giovanetti, M. R. Guarracino, and V. de Micco. 2012. Foraging rules of flower selection applied by colonies of Apis mellifera: ranking and associations of floral sources. Funct. Ecol. 26: 1186-1196.

Bagella, S., A. Satta, I. Floris, M. C. Caria, I. Rossetti, and J. Podani. 2013. Effects of plant community composition and flowering phenology on honeybee foraging in Mediterranean sylvo-pastoral systems. Appl. Veg. Sci. 16: 689-697.

Bartoń, K. 2016. MuMIn: Multi-model inference. R package version 1.15.6. https://CRAN.R-project.org/package=MuMIn (accessed 5 December 2017).

Bates, D., M. Mächler, B. M. Bolker, and S. C. Walker. 2015. Fitting linear mixed-effects models using lme4. J. Stat. Softw. 67: 1-48.

Battisti, A., I. Benvegnu, F. Colombari, and R. A. Haack. 2014. Invasion by the chestnut gall wasp in Italy causes significant yield loss in Castanea sativa nut production. Agr. Forest Entomol. 16: 75-79.

Blaschon, B., H. Guttenberger, N. Hrassnigg, and K. Crailsheim. 1999. Impact of bad weather on the development of the broodnest and pollen stores in a honeybee colony (Hymenoptera : Apidae). Entomol. Gen. 24: 49-60.

Bogdanov, S., P. Martin, and C. Lüllmann. 1997. Harmonised methods of the European Honey Commission. Apidologie Extra Issue 1-59. ISSN: 0044-8435.
Bogdanov, S., K. Bieri, V. Kilchenmann, and P. Gallmann. 2008. Mieli Uniflorali Svizzeri, ALP Forum 2005. Stazione di ricerca Agroscope Liebefeld-Posieux ALP, Centro di Ricerche Apicole, Berne, Switzerland.

Borowiec, N., M. Thaon, L. Brancaccio, S. Warot, E. Vercken, X. Fauvergue, N. Ris, and J.-C. Malausa. 2014. Classical biological control against the chestnut gall wasp "Dryocosmus kuriphilus" (Hymenoptera, Cynipidae) in France. Plant Prot. Q. 29: 9-12.

Brussino, G., G. Bosio, M. Baudino, R. Giordano, F. Ramello, and G. Melika. 2002. Pericoloso insetto esotico per il castagno europeo. Inf. Agrar. 58: $59-61$.

Castro-Vazquez, L., M. C. Diaz-Maroto, C. de Torres, and M. S. Perez-Coello. 2010. Effect of geographical origin on the chemical and sensory characteristics of chestnut honeys. Food Res. Int. 43: 2335-2340.

Conedera, M., P. Stanga, B. Oester, and P. Bachmann. 2001. Different postculture dynamics in abandoned chestnut orchards. For. Snow Landscape Res. 76: 487-492.

Conedera, M., P. Krebs, W. Tinner, M. Pradella, and D. Torriani. 2004. The cultivation of Castanea sativa (Mill.) in Europe, from its origin to its diffusion on a continental scale. Veg. Hist. Archaeobo. 13: 161-179.

Conedera, M., A. Quacchia, and E. Gehring. 2016. Castagno e infestazione da cinipide: pericolo scampato? Il Giardiniere 14: 65-67.

Crailsheim, K., U. Riessberger, B. Blaschon, R. Nowogrodzki, and N. Hrassnigg. 1999. Short-term effects of simulated bad weather conditions upon the behaviour of food-storer honeybees during day and night (Apis mellifera carnica Pollmann). Apidologie 30: 299-310.

EPPO (European and Meditteranean Plant Protection Organization). 2015. Dryocosmus kuriphilus. Bulletin OEPP/EPPO 35: 422-424

EPPO (European and Meditteranean Plant Protection Organization). 2017. Dryocosmus kuriphilus distribution. https://gd.eppo.int/taxon/DRYCKU/ distribution (accessed 5 December 2017).

Forster, B., T. Castellazzi, L. Colombi, E. Fürst, C. Marazzi, F. Meier, G. Tettamanti, and G. Moretti. 2009. Die Edelkastaniengallwespe Dryocosmus kuriphilus (Yasumatsu) (Hymenoptera, Cynipidae) tritt erstmals in der Südschweiz auf. Mitt. Schweiz. Entomol. Ges. 82: 271-279.

Gehring, E., M. Conedera, and G. Bosio. 2014. Edelkastaniengallwespe: ein weiteres problem für die kastanie. Bündner Wald 67: 24-27.

Gehring, E., B. Bellosi, A. Quacchia, and M. Conedera. 2017. Assessing the impact of Dryocosmus kuriphilius on the chestnut tree : branch architecture matters. J. Pest Sci. doi:10.1007/s10340-017-0857-9.

Gerlach, J. 1985. The dependence of honeybee behaviour on weather - shown by the results of weighting bee-hives in the period of 1969 to 1978 in the region of the beekeepers association of Hannover. Int. J. Biometeorol. 29: 67-85.

Gibbs, M., K. Schonrogge, A. Alma, G. Melika, A. Quacchia, G. N. Stone, and A. Aebi. 2011. Torymus sinensis: a viable management option for the biological control of Dryocosmus kuriphilus in Europe? Biocontrol 56: 527-538.

Gonnet, M., and G. Vache. 1985. Le goût du miel. UNAF. Paris, France.

Gonnet, M., and G. Vache. 1992. The taste of honey, Apimondia, Bucarest, Romania.

Guyot, C., A. Bouseta, V. Scheirman, and S. Collin. 1998. Floral origin markers of chestnut and lime tree honeys. J. Agric. Food Chem. 46: 625-633.

Jaeger, B. C., L. J. Edwards, K. Das, and P. K. Sen. 2017. An R-2 statistic for fixed effects in the generalized linear mixed model. J. Appl. Stat. 44: 1086-1105.

Johnson, P. C. D. 2014. Extension of Nakagawa \& Schielzeth's R-GLMM(2) to random slopes models. Methods Ecol. Evol. 5: 944-946.

Kotobuki, K., K. Mori, and Y. Sato. 1985. 2 methods to estimate the tree damage by chestnut gall wasp Dryocosmus-kuriphilus. Bull. Fruit Tree Res. Stn A (Yatabe) 2: 29-36.

Krebs, P., N. Koutsias, and M. Conedera. 2012. Modelling the eco-cultural niche of giant chestnut trees: new insights into land use history in southern Switzerland through distribution analysis of a living heritage. J. Hist. Geogr. 38: 372-386.

Krebs, P., W. Tinner, and M. Conedera. 2014. Del castagno e della castanicoltura nelle contrade insubriche: tentativo di una sintesi eco-storica. Archivio Storico Ticinese 155: 4-37. 
Matošević, D., N. Lacković, G. Melika, K. Kos, I. Franić, É. Kriston, M. Bozsó, G. Seljak, and M. Rot. 2015. Biological control of invasive Dryocosmus kuriphilus with introduced parasitoid Torymus sinensis in Croatia, Slovenia and Hungary. Period. Biol. 117: 471-477.

Maurizio, A., and F. Schaper. 1994. Das Trachtpflanzenbuch. Nektar und Pollen - die wichtigsten Nahrungsquellen der Honigbiene, 4th ed. Ehrenwirth Verlag GmbH, München, Germany.

Moriya, S., K. Inoue, and M. Mabuchi. 1990. The use of Torymus sinensis to control chestnut gall wasp, Dryocosmus kuriphilus, in Japan, pp. 94-105. In Bay-Petersen, J. (ed.), Proceedings of an International Seminar on the Use of Natural Enemies to Control Agricultural Pests, FFTC Book Series No. 40, 2-7 October 1989, Tsukuba, Japan.

Moriya, S., M. Shiga, and I. Adachi. 2003. Classical biological control of the chestnut gall wasp in Japan, pp. 407-415. In 1st International Symposium on Biological Control of Arthropods. USDA-Forestry Service. Honolulu Hawaii.

Müller, E., and H. R. Stierlin. 1990. Sanasilva Kronenbilder : mit Nadel- und Blattverlustprozenten. Eidgenössische Forschungsanstalt für Wald, Schnee und Landschaft, Birmensdorf.

Nakagawa, S., and H. Schielzeth. 2013. A general and simple method for obtaining R2 from generalized linear mixed-effects models. Methods Ecol. Evol. 4: 133-142.

Odoux, J. F., D. Feuillet, P. Aupinel, Y. Loublier, J. N. Tasei, and C. Mateescu. 2012. Territorial biodiversity and consequences on physico-chemical characteristics of pollen collected by honey bee colonies. Apidologie 43: 561-575.

Panzavolta, T., M. Bracalini, F. Croci, C. Campani, T. Bartoletti, G. Miniati, S. Benedettelli and R. Tiberi. 2012. Asian chestnut gall wasp in Tuscany: gall characteristics, egg distribution and chestnut cultivar susceptibility. Agr. Forest Entomol. 14: 139-145.

Payne, J. A., R. A. Jaynes, and S. J. Kays. 1983. Chinese chestnut production in the United States - Practice, problems, and possible solutions. Econ. Bot. 37: 187-200.

Persano Oddo, L., and R. Piro. 2004. Main European unifloral honeys: descriptive sheets. Apidologie 35: S38-S81.

Persano Oddo, L., M. Piazza, A. Sabatini, and M. Accorti. 1995. Characterization of unifloral honeys. Apidologie 26: 453-465.

Piana, M. L., L. Persano Oddo, A. Bentabolb, E. Bruneauc, S. Bogdanovd, and C. Guyot Declerck. 2004. Sensory analysis applied to honey: state of the art. Apidologie 35: S26-S37.

Pividori, M., F. Armando, and M. Conedera. 2005. Post cultural dynamics in a mixed chestnut coppice at its ecological border. Acta Hortic. 693: 219-224.
QGIS. 2016. Open Source Geospatial Foundation Project. http://www.qgis. org/ (accessed 5 December 2017).

Quacchia, A., S. Moriya, G. Bosio, I. Scapin, and A. Alma. 2008. Rearing, release and settlement prospect in Italy of Torymus sinensis, the biological control agent of the chestnut gall wasp Dryocosmus kuriphilus. BioControl 53: 829-839.

Quacchia, A., S. Moriya, R. Askew, and K. Schönrogge. 2014. Torymus sinensis: biology, host range and hybridization. Acta Hortic. 1043: 105-111.

R Core Team. 2017. R: a language and environment for statistical computing. $\mathrm{R}$ foundation for Statistical Computing, Vienna, Austria. https://www.Rproject.org/ (accessed 5 December 2017).

Rigling, D., S. Schütz-bryner, U. Heiniger, and S. Prospero. 2014. Der Kastanienrindenkrebs. Schadsymptome, Biologie und Gegenmassnahmen, pp 54. WSL Merkblatt, Birmensdorf.

Ruoff, K., W. Luginbühl, V. Kilchenmann, J. O. Bosset, K. Von Der Ohe, W. Von Der Ohe, and R. Amadò. 2007. Authentication of the botanical origin of honey using profiles of classical measurands and discriminant analysis*. Apidologie 38: 438-452.

Sartor, C., F. Dini, D. Torello Marinoni, M. G. Mellano, G. L. Beccaro, A. Alma, A. Quacchia, and R. Botta. 2015. Impact of the Asian wasp Dryocosmus kuriphilus (Yasumatsu) on cultivated chestnut: yield loss and cultivar susceptibility. Sci. Hort. 197: 454-460.

Seeley, T. D. 1986. Social foraging by honeybees: how colonies allocate foragers among patches of flowers. Behav. Ecol. Sociobiol. 19: 343-354.

Tinner, W., P. Hubschmid, M. Wehrli, B. Ammann, and M. Conedera. 1999. Long-term forest fire ecology and dynamics in southern Switzerland. J. Ecol. 87: 273-289.

Tuell, J. K., and R. Isaacs. 2010. Weather during bloom affects pollination and yield of highbush blueberry. J. Econ. Entomol. 103: 557-562.

Ugolini, F., L. Massetti, F. Pedrazzoli, R. Tognetti, A. Vecchione, L. Zulini, and G. Maresi. 2014. Ecophysiological responses and vulnerability to other pathologies in European chestnut coppices, heavily infested by the Asian chestnut gall wasp. Forest Ecol. Manag. 314: 38-49.

Yang, Y., M. J. Battesti, N. Djabou, A. Muselli, J. Paolini, P. Tomi, and J. Costa. 2012. Melissopalynological origin determination and volatile composition analysis of Corsican "chestnut grove" honeys. Food Chem. 132: 2144-2154.

Zuur, A., E. Ieno, N. Walker, A. Saveliev, and G. Smith. 2009. Mixed effects models and extensions in ecology with R. Springer Science+Business Media, New York. 